\title{
Mating behaviour of the marine turbellarian Macrostomum sp.: these worms suck
}

Received: 6 November 2003 / Accepted: 16 January 2004 / Published online: 4 March 2004

(C) Springer-Verlag 2004

\begin{abstract}
Simultaneous hermaphrodites experience unique conflicts of interest during reproduction, some of which are reflected in their complex mating behaviours. We here provide the first detailed description of the mating behaviour of a marine flatworm of the genus Macrostomum, a cosmopolitan group of microturbellaria. Mating in this species is usually initiated by the precopulatory behaviours circling and reeling, then leads to reciprocal copulation where worms mutually insert their copulatory stylet, and often ends in an intriguing postcopulatory sucking behaviour. We provide detailed data on the frequencies and durations of the different behaviours, and examine some biotic and abiotic factors that could influence the mating rate. We further speculate on the function of sucking and suggest that it could be an adaptation for the digestion of sperm and/or the removal of seminal components, which may function as allohormones.

Electronic Supplementary Material Supplementary material is available in the online version of this article at http://dx.doi.org/10.1007/s00227-004-1314-x.
\end{abstract}

Communicated by O. Kinne, Oldendorf/Luhe

L. Schärer $(\square) \cdot$ P. Sandner

Department of Evolutionary Biology,

Institute of Animal Evolution and Ecology,

University of Münster, Hüfferstrasse 1, 48149 Münster, Germany

E-mail: lukas.scharer@uibk.ac.at

Tel.: + 43-512-5076170

Fax: $+43-512-5072930$

G. Joss

Department of Biological Sciences, Macquarie University, 2109 North Ryde (Sydney), NSW, Australia

Present address: L. Schärer

Division of Ultrastructural Research and Evolutionary Biology, Institute of Zoology and Limnology, University of Innsbruck, Technikerstrasse 25, 6020 Innsbruck, Austria

\section{Introduction}

Turbellaria are a highly diverse group of flatworms. They represent a taxonomically ill-defined group among the Platyhelminthes, which are currently undergoing major revision (Jondelius 1998; Littlewood et al. 1998; Jondelius et al. 2002; Telford et al. 2003). Most turbellaria are simultaneous hermaphrodites (Ghiselin 1969), and they are therefore interesting study organisms to investigate questions of hermaphroditic reproduction, such as sex allocation, sperm competition, mating conflicts and mate manipulation (e.g. Charnov 1979; Michiels 1998; Schärer and Ladurner 2003). Moreover, some intriguing reproductive patterns, such as conditional gamete trading (Fischer 1980, 1987; Leonard and Lukowiak 1984; Sella 1985), hypodermic impregnation (Apelt 1969; Michiels 1998), and sperm digestion (Sluys 1989; Greeff and Michiels 1999; Westheide 1999; Bojat et al. 2001) occur in hermaphrodites. However, with a few exceptions, very little is known about their mating behaviour.

Most of the available data covers the larger turbellaria, such as triclads, and among those especially planarians (e.g. Peters et al. 1996; Vreys and Michiels 1997, 1998; Michiels and Bakovski 2000) and polyclads (Michiels and Newman 1998). For microturbellaria there is some information on Acoela (Hyman 1937; Costello and Costello 1938; Apelt 1969) and Proseriata (Giesa 1966), and a few older reports that provide some, mostly anecdotal, observations for a variety of species (e.g. Hallez 1879; Bresslau 1928; Meixner 1938). We are aware of only one report that gives a description of the mating behaviour of a species of Macrostomum (Ax and Borkott 1968). It consists of a short movie that shows, among other things, a copulation and sperm transfer in $M$. romanicum (called $M$. salinum in the publication).

We have recently established a member of the genus Macrostomum (Rhabditophora: Macrostomida) as a model organism, to address the above-mentioned questions. During this work we observed elements in the 
mating behaviour that may be of interest for future studies on mating conflict and sperm digestion. These, however, require a detailed description of and clear terminology for the different behaviours, which we provide in the present study. Our description of the copulation behaviour of Macrostomum sp. is based on detailed microscopic observations, and provides quantitative data on the occurrence and duration of different behavioural components. We further suggest a hypothesis for the function of the observed postcopulatory behaviour.

\section{Materials and methods}

Study animal

Macrostomum sp. (Rhabditophora: Macrostomida) is a member of the interstitial sand fauna of the northern Adriatic Sea (Ladurner et al. 2000). It is an outcrossing simultaneous hermaphrodite (Schärer and Ladurner 2003), and reaches $1.5 \mathrm{~mm}$ in length when fully grown. It is transparent, allowing non-invasive observation of internal structures (Fig. 1). The paired testes are located anterior to the paired ovaries, and the female genital pore is anterior to the male genital pore. The female genital pore opens into the female atrium, into which sperm are transferred during copulation. The male genital pore is associated with a sclerotic stylet that serves as a copulatory organ, with a false seminal vesicle (i.e. the enlarged end

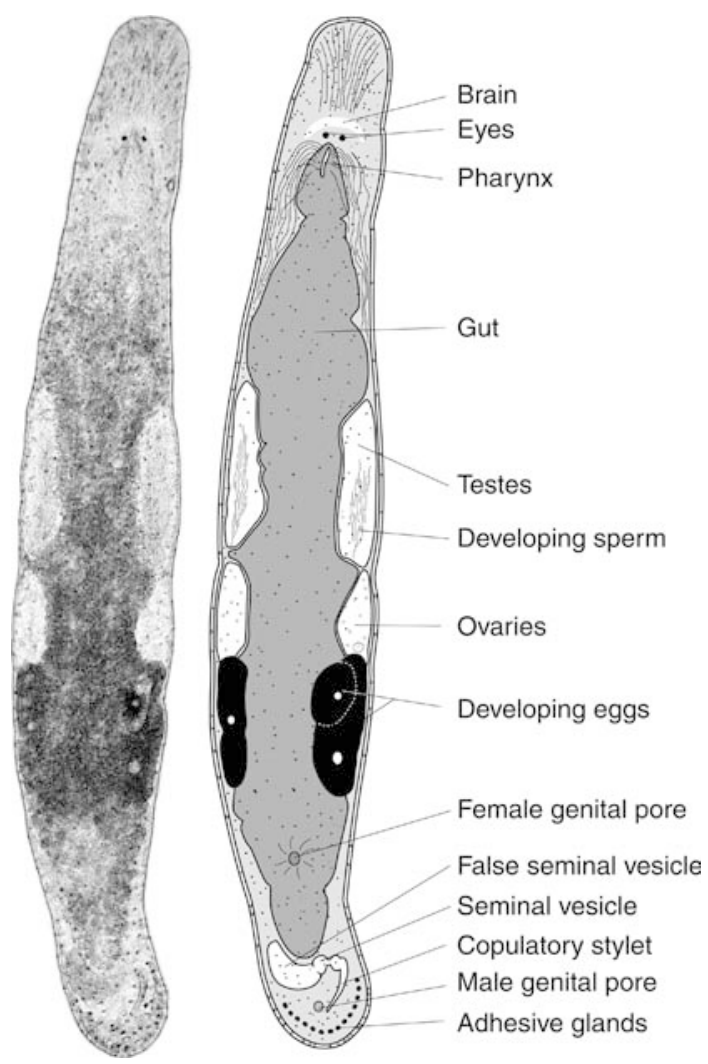

Fig. 1 Macrostomum sp. Photograph and line drawing of an adult, showing the main components of the reproductive system. Note the relative positions of the male and female genital openings, which is important to interpret the copulatory postures. Total length of worm is about $1.5 \mathrm{~mm}$ of the vas deferens) that contains the sperm to be used in future copulations and with a muscular seminal vesicle that pumps the sperm. Sperm are complex (Fig. 2A), and copulations are frequent and reciprocal. Received sperm can often be observed in the female atrium, where sperm heads stick in a specialised tissue that connects to the oviduct (Fig. 2B), and sperm often move vigorously. Eggs start to form posterior to the ovary, gradually increase in size during vitellogenesis and enter the female atrium, generally one at a time, where they remain for some time before being laid. Mass cultures of Macrostomum sp. have been initiated at the University of Innsbruck in 1995 according to culture conditions described elsewhere (Tyler 1981; Rieger et al. 1988), and were recently established at the University of Münster. Briefly, worms are maintained at $20^{\circ} \mathrm{C}$ in glass petri dishes containing $f / 2$ medium (a nutrient-enriched artificial seawater, Guillard and Ryther 1962), and are fed with the diatom Nitzschia curvilineata. Generation time under these conditions is 18 days, 5 days from egg laying to hatching and 13 days from hatching to adult.

\section{Methods of observation}

Worms usually move in three dimensions, and frequently move along the walls of culture dishes, making direct observation difficult under these conditions. We therefore devised an observation chamber that allows us to observe worms in a two-dimensional plane, by placing them in a drop of $f / 2$ medium between two microscope slides (Fig. 3). Depending on the purpose of the observation we varied the distance between the slides. Thin observation chambers used a $105 \mu \mathrm{m}$ spacer (i.e. one HERMA photo sticker), in which worms touch both slides and thereby are slightly compressed, facilitating observation of internal structures. Thick observation chambers used a $210 \mu \mathrm{m}$ spacer (i.e. two HERMA photo stickers), in which worms would generally move on either the upper or lower slide. In order to avoid evaporation six additional drops of $f / 2$ were added next to the drops containing the worms and the whole observation chamber was sealed with pure white Vaseline. We have successfully kept worms in such observation chambers for at least 10 days. Worms appear to show normal behaviour, including egg laying, normal embryonic development and successful hatching of offspring. No food was provided during the observation period, as the excreted algae can interfere with the image analysis algorithm.

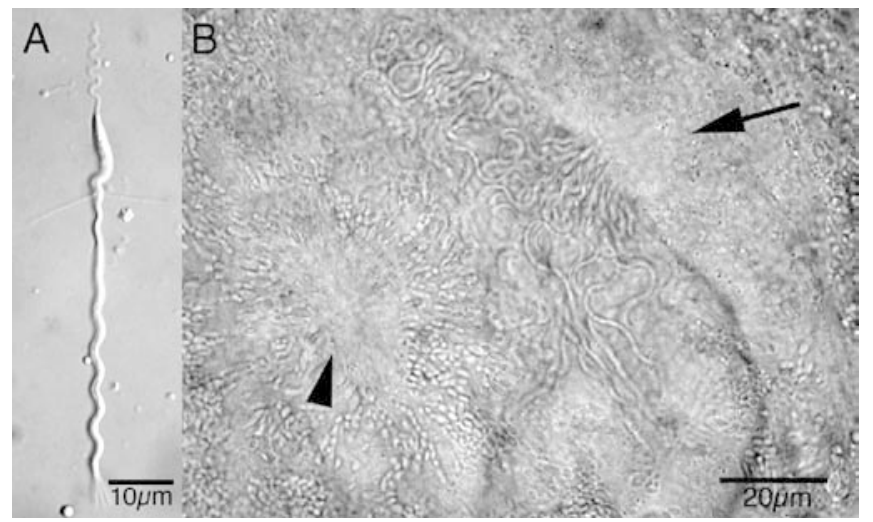

Fig. 2A, B Sperm of Macrostomum sp. A Sperm under interference contrast illumination. Note tapering end (which produces rapid undulations), two lateral bristles and blunt end (which looks like small brush). B Received sperm in the female atrium. Note that sperm stick in a specialised tissue with the tapering end and possibly the bristles (arrow). Also note the position of the female genital opening (arrowhead), which is surrounded by granular gland secretions 

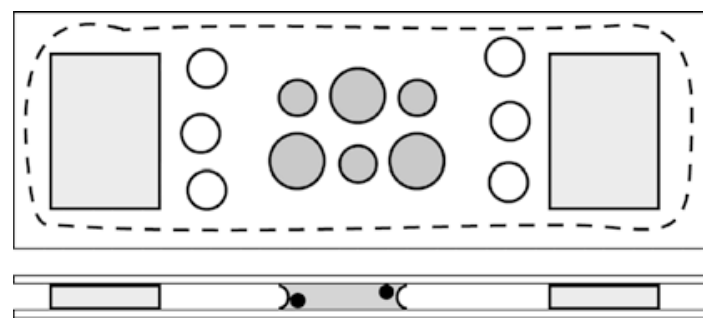

Fig. 3 Top view and longitudinal section through an observation chamber. The observation chamber consists of two microscope slides that are glued together with photo stickers (light grey). By varying the number of photo stickers one can vary the distance between the slides. Before joining the two slides, drops containing the worms to be observed (six central grey circles) and drops to reduce evaporation (peripheral white circles) are placed on one of the slides, and are encircled with pure white Vaseline (dashed black line). In the longitudinal section the space between the slides is exaggerated, and only one drop is depicted (small black circles indicate cross sections through the worms). Under a microscope the rim of the drop appears as a dark circle with the meniscus bowed inwards, keeping worms in the observable area

\section{Description of the mating behaviour}

In order to provide an initial description of the different elements of the mating behaviour we prepared many observation chambers that usually contained only one drop with one pair, and which were subsequently observed under an Olympus BH-2 compound microscope at various magnifications. Adult worms used for these observations usually stemmed from the mass cultures, and were chosen arbitrarily. Periods of these observations were recorded as digital QuickTime movies, using a Sony DFW-X700 digital FireWire c-mount camera connected to a PowerMac G4/450 running the shareware BTV Pro (http://www.bensoftware.com/btvpro.html). This set-up allows digital movie capture at a maximum of about 8 frames $\mathrm{s}^{-1}$ at the native resolution of the camera $(1,024 \times 768)$. In order to achieve higher frame rates for more detailed observations some movies were made with a Sony CCD Iris video camera attached to a Sony DV Walkman, and subsequently transferred to the computer using BTV Pro.

\section{Quantitative description of the mating behaviour}

Mating could be a simple function of the frequency with which worms encounter each other, which could in turn be a function of the size of the enclosure in which the worms find themselves. In order to evaluate this possibility, the effect of enclosure size on the copulation rate was investigated. Enclosure size was varied by varying drop size in a range from 0.6 to $4.7 \mu \mathrm{l}$, which corresponded to drop areas of 2.6-22.0 $\mathrm{mm}^{2}$ (median: $8.9 \mathrm{~mm}^{2}$ ). Eight observation chambers with six drops, each containing one pair of worms, were made over a period of 5 days $(n=48)$. Each observation chamber was filmed for exactly $4 \mathrm{~h}$ at 1 frame $\mathrm{s}^{-1}$, yielding 14,400 frames per QuickTime movie. Movie capture was initiated within 5 min after the observation chamber was assembled. The size of each worm was estimated as the mean of three area measurements taken from the movies.

The movies were analysed in three ways. (1) We determined the number of times worms encountered each other with a custommade image analysis algorithm (available from the authors) that was programmed in the public domain image analysis software ImageJ (available at http://rsb.info.nih.gov/ij/). The program progressively buffers a user-specified set of frames from the movie and automatically segments the worm outlines from the enclosure and debris (e.g. eggs or excreted algae). All the outlines are recorded in a dataset and can be interactively verified against the original movie images. Encounters were scored as the times at which two separate outlines merged to one (i.e. whenever the worms came in contact). (2) We determined the number of times the different reproductive behaviours occurred by manual frame-by-frame analysis of the QuickTime movies. Behavioural elements were recorded in time slices of ten frames (i.e. 1,440 time slices), which provided a sufficiently high temporal resolution. We determined the time of copulation and the occurrence of postcopulatory behaviour. To estimate the temporal distribution of the copulatory behaviour, we calculated the median copulation time for each pair. If any eggs were laid, we further noted the time of egg deposition and also calculated the median egg-laying time. (3) We determined the durations of the different reproductive behaviours. We did this by picking one copulation for each pair at random (excluding the first and last copulations). By manual frame-by-frame analysis of the QuickTime movies we determined the duration of the precopulatory behaviour, the duration of the copulation, the occurrence and duration of the postcopulatory behaviour, and the time until the next copulation.

\section{Statistical analysis}

Of the 48 drops, 11 had to be excluded form the analysis (five because one or both worms appeared to have been injured during pipeting, three because one worm appeared to be immature, and three because the drop did not touch the upper slide). The remaining sample size was thus $n=37$. We graphically checked if data fulfilled the assumptions of parametric test statistics, and transformed the data if necessary. If no suitable transformation could be found, we used nonparametric statistics. For all statistical tests we give two-tailed error probabilities. Averages are always given as means $( \pm 1 \mathrm{SE})$ unless otherwise stated. Data were analysed with JMP 3.2.2. (SAS Institute 1994).

\section{Results}

\section{Description of the mating behaviour}

Worms copulated readily in the observation chambers, and all elements of the behaviour could easily be observed. The precopulatory behaviour consists of two elements, circling and reeling, that can alternate (Fig. 4). Circling consists of the worms mutually crawling on each other, often forming a tight ball. Proper circling can only occur if both partners detach from the substrate by releasing the adhesive glands on their tail plates. If one remains attached, the other may circle around the attached individual, but copulation cannot occur. During reeling worms take on a head to tail orientation, with the snout of one individual touching the other individual dorsally anywhere between the tip of the tail to the location opposite the female opening. In this posture the worms can often be seen "reeling" around their centre of mass in the direction of the heads. Frequently the worms will show an "erection", a raising of the tissue surrounding the copulatory stylet, which appears as a translucent cone-like shape in the tail plate (see arrowheads in Fig. 4) and which suggests that reeling is sexually motivated. Another characteristic of reeling is that there is a gap in the centre of the reel. Reeling is less frequent than circling and is not a prerequisite for copulation. Both behaviours can occur without leading to a copulation. 
Fig. 4 Macrostomum sp. Key frames from a video sequence (with line drawings) of the precopulatory circling and reeling behaviours of a pair of adults. In this sequence circling occurs from the start to the frame at $2.3 \mathrm{~s}$ and reeling in frames from 3.3 to $8.9 \mathrm{~s}$. The depicted sequence did not lead to a copulation. The bowed arrows in the line drawings indicate that the pair turned $360^{\circ}$ from one frame to the next. Arrowheads indicate "erections", a cone-like swelling around the copulatory stylet. The full video sequence is available as a QuickTime movie (see supplementary materials S1 and S2 for a small and large version respectively)
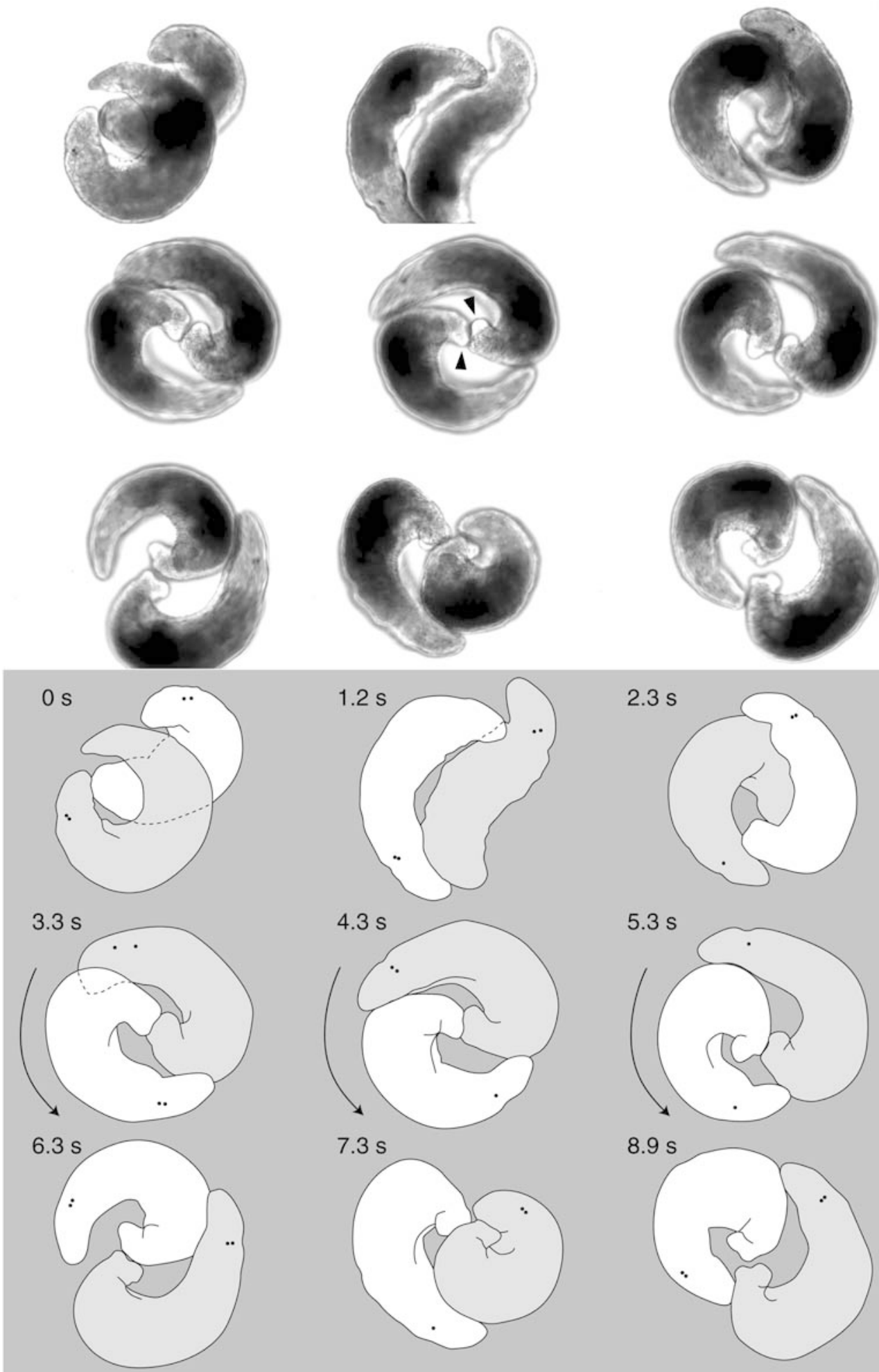

$2.3 \mathrm{~s}$
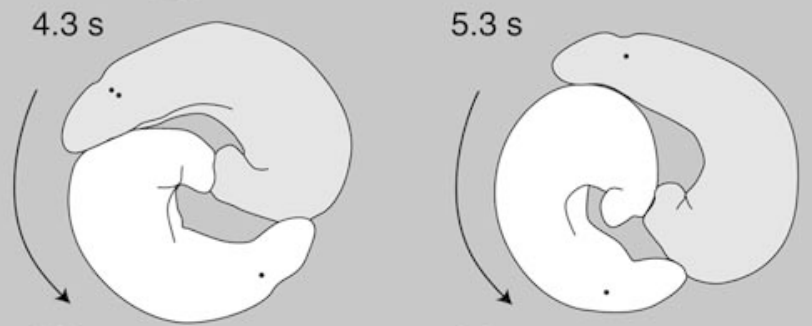

$7.3 \mathrm{~s}$

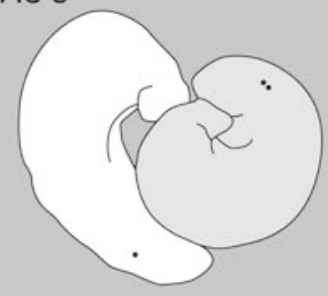

$8.9 \mathrm{~s}$

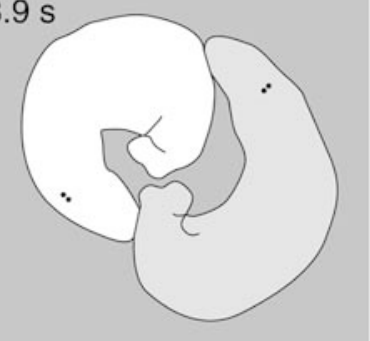

The copulation consists of a posture where the tail plates touch each other ventrally in opposing directions, while the anterior ventral surface of each worm touches the posterior dorsal surface of the partner (Fig. 5). The shape of the individual worm in this posture resembles a $\mathrm{G}$ (Fig. 5, for a graphical representation see the two small interlocking Gs next to the worms at $9.5 \mathrm{~s}$ ).
Together the worms form a tight disc that lies on the substrate with no gap between them. In this posture worms often rotate around their centre of mass, as described for reeling. In thin observation chambers worms could be observed to reciprocally insert their stylet in the female opening of their partners, but sperm transfer was never clearly observed. 
Fig. 5 Macrostomum sp. Key frames from a video sequence (with line drawings) of the copulatory and postcopulatory behaviours of a pair of adults. Copulation (frames at 7.8$19.5 \mathrm{~s}$ ) is preceded by a short phase of circling (from the start to the frame at $5.8 \mathrm{~s}$ ), and ends in a suck (frames at 28.3-

34.8 s). Note: (1) the bundle of sperm sticking out of the female opening on the last picture $(37.3 \mathrm{~s}$, the small inset shows this in more detail); (2) the small graphical representation of the G-position during mating next to the worms at $9.5 \mathrm{~s}$; and (3) the small graphical representation of the $\Omega$-position during sucking next to the worm at $31.8 \mathrm{~s}$. The full video sequence is available as a QuickTime movie (see supplementary materials S3 and S4 for a small and large version respectively)
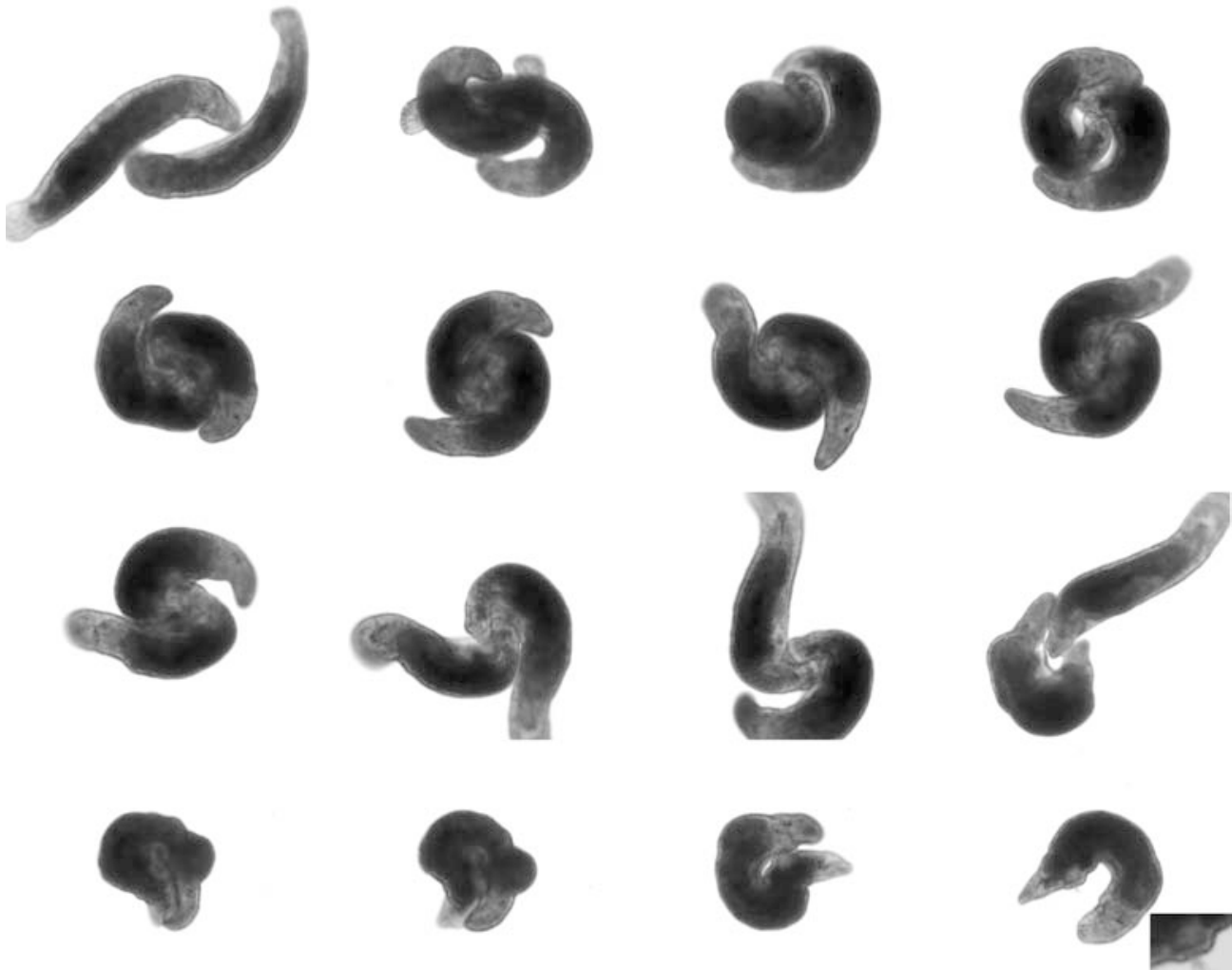

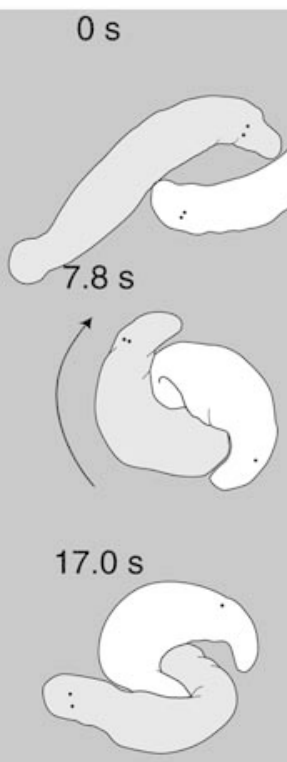

$28.3 \mathrm{~s}$

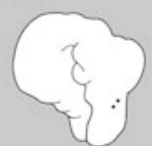

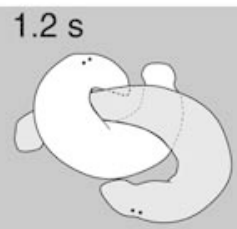

$9.5 \mathrm{~s}$

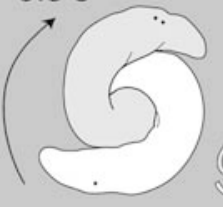

$19.5 \mathrm{~s}$

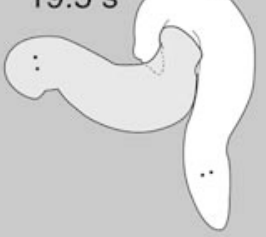

$31.8 \mathrm{~s}$

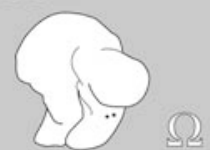

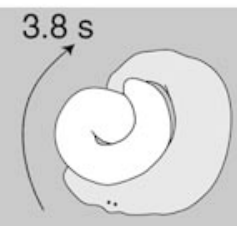

$12.0 \mathrm{~s}$
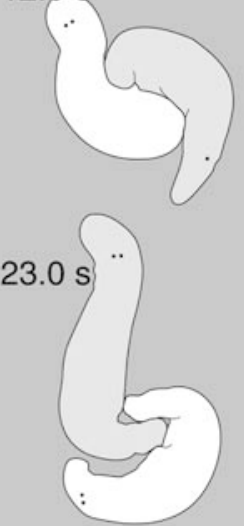

$34.8 \mathrm{~s}$

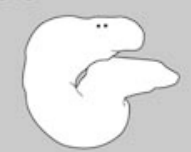

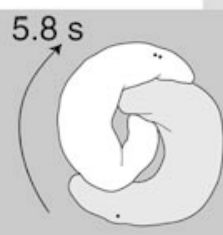

$14.5 \mathrm{~s}$
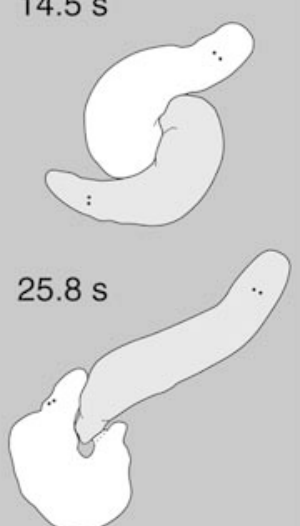

$37.3 \mathrm{~s}$
The postcopulatory behaviour is facultative, and can be exhibited by none, one, or both worms. It consists of a stereotypical sucking posture (Fig. 5), which resembles an $\Omega$-shape, and in which the worm folds back onto itself while positioning its pharynx over its female opening (Fig. 5, for a graphical representation see the small $\Omega$ next to the worms at $31.8 \mathrm{~s}$ ). In thin observation chambers and at high resolution, one can observe that the pharynx is performing a sucking behaviour. After the pharynx disengages one can often 
observe a bundle of sperm sticking out of the female opening (Fig. 5).

Quantitative description of the mating behaviour

Worms on average encountered each other 418 times over the 4-h period (range: 136-970, every 15-106 s), and there was a clear relationship between the size of the drop in which worms were held and the number of encounters (Spearman rank correlation, $r_{\mathrm{s}}=-0.55$, $P<0.001)$.

We observed a total of 885 copulations. Worms copulated on average 24 times over the 4-h period (range: 5-55). Copulations lasted $8.8 \pm 0.4$ s (range: 5$16 \mathrm{~s}$, coefficient of variation $=30.6, n=37$ ), and were preceded by a precopulatory phase of $15.9 \pm 1.7 \mathrm{~s}$ (range: $5-49 \mathrm{~s}, \mathrm{CV}=66.5$ ). The mean duration until the next copulation was $613 \pm 158 \mathrm{~s}$ (range: 50-5,140 s). Despite the strong relationship between drop size and the number of encounters, we found no significant relationship between drop size and the number of copulations $\left(r_{\mathrm{s}}=-0.17, P=0.31\right)$, nor between the number of encounters and the number of copulations $\left(r_{\mathrm{s}}=0.23\right.$, $P=0.16$ ), suggesting that the number of copulations is not a simple function of either of these parameters. There also appeared to be no effects of the average size of the pair $\left(r_{\mathrm{s}}=0.09, P=0.62\right)$ or the relative size difference between the worms in the pair $\left(r_{\mathrm{s}}=0.22\right.$, $P=0.18)$ on the number of copulations.

However, we observed a clear trend for more copulations to occur later in the observation period, as measured by the total numbers of copulations observed in all pairs in the first, second, third and fourth hour (123, 223, 242, and 298 copulations, respectively). As a result, the mean of the median copulation time of each pair was 142.5 min after the start of the observation, which is significantly later than expected if copulations were spread equally over the 240 -min observation period (one-sample $t$-test against the expected median copulation time of $120 \mathrm{~min}, t=3.7, P<0.001)$. Some pairs alternated active copulatory periods with periods of resting or fast swimming, whereas other pairs copulated at a relatively constant rate.

We observed a total of 1,090 sucks; $76 \%$ of these occurred within $5 \mathrm{~s}$ after the end of a copulation, and there was a strong correlation between the number of copulations and the number of sucks within a pair $\left(r_{\mathrm{s}}=0.79, P<0.001\right)$. Nevertheless, 258 sucks occurred independent of a copulatory event, suggesting that sucking is not only a postcopulatory behaviour. The average suck lasted for $4.9 \pm 0.2 \mathrm{~s}$ (range: 4-7 s, $\mathrm{CV}=18.7)$. The low $\mathrm{CV}$ suggests that sucking is highly stereotypic. Of the 885 copulations we observed, $33 \%$ were not followed by a suck, $40 \%$ were followed by one individual performing sucking behaviour, and in the remaining $27 \%$ cases both partners performed a suck.

Of the 37 pairs, 28 laid a total of 44 eggs during the 4-h observation period (i.e. 1, 2, 3, and 5 eggs were laid by $17,8,2$ and 1 pairs, respectively). This suggests a per capita egg-laying rate of 0.6 eggs in $4 \mathrm{~h}$ or 3.6 eggs day $^{-1}$. This is substantially higher than the normally observed rate of about 1-2 eggs day ${ }^{-1}$ (L. Schärer, unpublished data), and suggests that the transfer to these small observation chambers stimulated egg laying. Moreover, the mean of the median egg-laying time was $50.4 \mathrm{~min}$, which is significantly earlier than expected if laying were spread equally over the 240-min observation period (one-sample $t$-test against the expected egg laying time of $120 \mathrm{~min}, t=4.8, P<0.001, n=28)$.

\section{Discussion}

A striking aspect of the mating behaviour of Macrostomum $\mathrm{sp}$. is the high mating rate. Given that these worms usually lay only 1 or 2 eggs day ${ }^{-1}$, and that they therefore need only a few sperm to fertilise them, the high mating rate is unlikely to be explained by assurance of fertility. We also do not think that the high mating rates are an artefact of the spatially constrained holding conditions in the observation chambers. Copulations are readily observed under the normal culture conditions, in which hundreds of worms are kept in glass petri dishes at densities that are about two orders of magnitude lower. Moreover, we found no significant effect of drop size on copulation rate, suggesting that this factor is not very important. Further, we have observed comparable copulation rates in worms that had recently been caught in the field, thus excluding a possible artefact of longterm laboratory maintenance.

Although there can be no doubt that sperm are transferred between worms (Schärer and Ladurner 2003), we have never observed sperm transfer in direct observations. One possible reason could be that many copulations do not actually lead to sperm transfer, which could partly explain the high mating rate. Alternatively, if only few sperm were transferred in each copulation, it may be difficult to see the transfer. In the video documentation of the mating behaviour of $M$. romanicum presented by Ax and Borkott (1968), hundreds, if not thousands of sperm are transferred in one copulation. This is clearly not the case in our species. A well-filled seminal vesicle probably contains only between 100 and 200 sperm (L. Schärer, unpublished data), and sperm transfer at the rate observed in $M$. romanicum would clearly be unsustainable at the observed mating rates. Moreover, we have repeatedly observed that small numbers of sperm can pass through an everted stylet after a failed copulation attempt. We thus consider it likely that sperm are transferred frequently, but in relatively small numbers.

The functions of circling and reeling could be linked to courtship, mate assessment, or may just be the outcome of an attempt to assume the copulatory posture. The need to get in close contact for copulation may require the mutual crawling on each other seen in circling. However, circling sometimes appeared to be performed 
primarily by one worm on the other, as may be expected for courtship behaviour. But, as we could not clearly distinguish the individual worms in a pair, we did not attempt to analyse this. Marking the worms with vital dyes would be required to study this possibility in more detail. Regarding mate assessment, we presume that the close proximity during circling could allow the worms to sense the presence of developed eggs in the body of their partners, and that this could influence their attractiveness. Reeling, in contrast, may simply represent a failed attempt to assume the copulatory posture.

However, the most interesting finding is the peculiar postcopulatory sucking behaviour. Although its function remains unknown, we would like to propose a few possibilities. Since $76 \%$ of all sucks occurred directly after a copulation event, they must be a consequence of something that happens during copulation. When the pharynx disengages after sucking we have often observed a bundle of sperm that was sticking out of the female genital opening; this was never observed in any other context. We initially considered the possibility that the observed structures are the cilia of the vagina, but these are much shorter, and are thinner than sperm. One possible explanation for sucking could be that the worms eat the sperm they just received. Sperm digestion is a well-known phenomenon in hermaphroditic animals, and it occurs in a wide range of species (e.g. Sluys 1989; Baur 1998; Michiels 1998; Westheide 1999). However, it usually occurs via resorptive tissues in the spermreceiving organs or via ducts that connect these organs with the gut. We are aware of only two other species where a recipient was observed to directly eat the received sperm. One is in the arrowworm Spadella cephaloptera (John 1933), an organism exhibiting pseudocopulation, whereby the sperm are deposited on the outside of the body and then migrate into the female opening. The other case is in the leech Placobdella parasitica; in this case, the spermatophores are deposited externally, then dissolve the body wall, and the sperm enter the animal hypodermically (Myers 1935).

An interesting observation about sucking is that the sperm in the bundle all appear to have the same length when sticking out of the female opening. One possible explanation could be that this occurs because they remain attached internally (as shown in Fig. 2B). The female atrium can contract very strongly (such as during egg laying), and it is thus conceivable that the lose ends of the attached sperm and the free sperm could be pressed out through the female opening, and any free sperm eaten. To show this convincingly will require following the fate of labelled sperm in the recipient, and determining if sperm are actually digested when taken up orally.

During copulation Macrostomum sp. does not only transfer sperm, but also prostate secretions. Recently mated worms sometimes have translucent granules in their female atrium, which could represent coagulated prostate secretions. The structure of the prostate glands has not been studied in detail in our species, but prostate glands are a prominent feature of the tail plate in many Macrostomidae (Doe 1982), and they sometimes reach dramatic sizes (e.g. M. miraculicis in Schmidt and Sopott-Ehlers 1976, called Bradburia miraculicis in Faubel et al. 1994). The function of the prostate secretion remains unknown. Older literature often states that it may be involved in nourishing sperm, but we are aware of no convincing evidence for this idea. However, recent ideas about mate manipulation via allohormones could apply (e.g. Michiels 1998; Koene and ter Maat 2001). Experimental studies in Drosophila have convincingly shown that male accessory gland proteins influence a number of female reproductive traits to the advantage of the male (Holland and Rice 1999; Pitnick et al. 2001), but that they can be harmful for the receiving female (Chapman et al. 1995). It therefore seems plausible that recipients of such manipulating allohormones attempt to remove them, and sucking may be involved in this.

Finally, one could imagine that the high mating frequency is linked to sucking. To transfer few sperm per mating may make sucking less rewarding and may hence be a strategy to increase the chances of depositing sperm that have a chance to fertilize the next egg.

Acknowledgements We would like to thank M. Fasel for artwork and P. Ladurner for the sperm picture. P. Ladurner, N. Michiels, R. Rieger and D. Vizoso provided helpful discussion and comments on the manuscript. L.S. would further like to thank N. Michiels for his hospitality. During this study L.S. was supported by an IHP-fellowship (SNF, Switzerland) and a L.-Meitner-fellowship (FWF, Austria). Animal experimentation was carried out in accordance to German legal and ethical standards.

\section{References}

Apelt G (1969) Fortpflanzungsbiologie, Entwicklungszyklen und vergleichende Frühentwicklung acoeler Turbellarien. Mar Biol 4:267-325

Ax P, Borkott H (1968) Organisation und Fortpflanzung von Macrostomum romanicum (Turbellaria, Macrostomida). Institut für den wissenschaftlichen Film, Göttingen

Baur B (1998) Sperm competition in molluscs. In: Birkhead TR, Møller AP (eds) Sperm competition and sexual selection. Academic, London, pp 255-305

Bojat NC, Sauder U, Haase M (2001) The spermathecal epithelium, sperm and their interactions in the hermaphroditic land snail Arianta arbustorum (Pulmonata, Stylommatophora). Zoomorphology 120:149-157

Bresslau E (1928) Turbellaria. Walter de Gruyter, Berlin

Chapman T, Liddle LF, Kalb JM, Wolfner MF, Partridge L (1995) Cost of mating in Drosophila melanogaster females is mediated by male accessory gland products. Nature 373:241-244

Charnov EL (1979) Simultaneous hermaphroditism and sexual selection. Proc Natl Acad Sci 76:2480-2484

Costello HM, Costello DP (1938) Copulation in the acoelous turbellarian Polychoerus carmelensis. Biol Bull (Woods Hole) 75:85-98

Doe DA (1982) Ultrastructure of copulatory organs in Turbellaria. 1. Macrostomum sp. and Microstomum sp. (Macrostomida). Zoomorphology 101:39-60

Faubel A, Blome D, Cannon LRG (1994) Sandy beach meiofauna of eastern Australia (southern Queensland and New South Wales). 1. Introduction and Macrostomida (Platyhelminthes). Invertebr Taxon 8:989-1007 
Fischer EA (1980) The relationship between mating system and simultaneous hermaphroditism in the coral reef fish, Hypoplectrus nigricans (Serranidae). Anim Behav 28:620-633

Fischer EA (1987) Mating behavior in the black hamlet gamete trading or egg trading. Environ Biol Fishes 18:143-148

Ghiselin MT (1969) The evolution of hermaphroditism among animals. Q Rev Biol 44:189-208

Giesa S (1966) Die Embryonalentwicklung von Monocelis fusca Oersted (Turbellaria, Proseriata). Z Morphol Oekol Tiere $57: 137-230$

Greeff JM, Michiels NK (1999) Sperm digestion and reciprocal sperm transfer can drive hermaphrodite sex allocation to equality. Am Nat 153:421-430

Guillard RR, Ryther JH (1962) Studies on marine planktonic diatoms. I. Cyclotella nana Hustedt and Detonula confervacaea (Cleve) Gran. Can J Microbiol 8:229-239

Hallez P (1879) Contibutions a l'histoire naturelle des Turbellariés. Trav Inst Zool Lille Stn Wimereux II:viii + 224

Holland B, Rice WR (1999) Experimental removal of sexual selection reverses intersexual antagonistic coevolution and removes a reproductive load. Proc Natl Acad Sci 96:50835088

Hyman LH (1937) Reproductive system and copulation in Amphiscolops langerhansi (Turbellaria, Acoela). Biol Bull (Wood Hole) 72:319-326

John CC (1933) Habits, structure and development of Spadella cephaloptera. Q J Microsc Sci 75:625-696

Jondelius U (1998) Flatworm phylogeny from partial 18S rDNA sequences. Hydrobiologia 383:147-154

Jondelius U, Ruiz-Trillo I, Baguña J, Riutort M (2002) The Nemertodermatida are basal bilaterians and not members of the Platyhelminthes. Zool Scr 31:201-215

Koene JM, ter Maat A (2001) "Allohormones": a class of bioactive substances favoured by sexual selection. J Comp Physiol A 187:323-326

Ladurner P, Rieger RM, Baguña J (2000) Spatial distribution and differentiation potential of stem cells in hatchlings and adults in the marine platyhelminth Macrostomum sp.: a bromodeoxyuridine analysis. Dev Biol 226:231-241

Leonard JL, Lukowiak K (1984) Male-female conflict in a simultaneous hermaphrodite resolved by sperm trading. Am Nat 124:282-286

Littlewood DTJ, Bray RA, Clough KA (1998) A phylogeny of the Platyhelminthes: towards a total-evidence solution. Hydrobiologia 383:155-160

Meixner J (1938) Turbellaria (Strudelwürmer). I. Allgemeiner Teil. In: Grimpe G, Wagler E, Remane A (eds) Die Tierwelt der Nord- und Ostsee. Akademischer, Leipzig, pp 1-146
Michiels NK (1998) Mating conflicts and sperm competition in simultaneous hermaphrodites. In: Birkhead TR, Møller AP (eds) Sperm competition and sexual selection. Academic, London, pp 219-254

Michiels NK, Bakovski B (2000) Sperm trading in a hermaphroditic flatworm: reluctant fathers and sexy mothers. Anim Behav 59:319-325

Michiels NK, Newman LJ (1998) Sex and violence in hermaphrodites. Nature 391:647

Myers (1935) Behaviour and morphological changes in the leech Placobdella parasitica during hypodermic insemination. JMorphol 57:617-653

Peters A, Streng A, Michiels NK (1996) Mating behaviour in a hermaphroditic flatworm with reciprocal insemination: do they assess their mates during copulation? Ethology 102:236-251

Pitnick S, Brown WD, Miller GT (2001) Evolution of female remating behaviour following experimental removal of sexual selection. Proc R Soc Lond Ser B 268:557-563

Rieger RM, Gehlen M, Haszprunar G, Holmlund M, Legniti A, Salvenmoser W, Tyler S (1988) Laboratory cultures of marine Macrostomida (Turbellaria). Fortschr Zool 36:523

SAS Institute (1994) JMP statistics and graphics guide, version 3. SAS Institute, Cary, N.C., USA

Schärer L, Ladurner P (2003) Phenotypically plastic adjustment of sex allocation in a simultaneous hermaphrodite. Proc R Soc Lond Ser B 270:935-941

Schmidt P, Sopott-Ehlers B (1976) Interstitielle Fauna von Galapagos. XV. Macrostomum O. Schmidt, 1948 und Siccomacrostomum triviale nov. gen. nov. spec. (Turbellaria, Macrostomidae). Mikrofauna des Meeresbodens 57:1-45

Sella G (1985) Reciprocal egg trading and brood care in a simultaneous polychaete worm. Anim Behav 33:938-944

Sluys R (1989) Sperm resorption in triclads (Platyhelminthes, Tricladida). Invertebr Reprod Dev 15:89-95

Telford MJ, Lockyer AE, Cartwright-Finch C, Littlewood DTJ (2003) Combined large and small subunit ribosomal RNA phylogenies support a basal position of the acoelomorph flatworms. Proc R Soc Lond Ser B 270:1077-1083

Tyler S (1981) Development of cilia in embryos of the turbellarian Macrostomum. Hydrobiologia 84:231-239

Vreys C, Michiels NK (1997) Flatworms flatten to size up each other. Proc R Soc Lond Ser B 264:1559-1564

Vreys C, Michiels NK (1998) Sperm trading by volume in a hermaphroditic flatworm with mutual penis intromission. Anim Behav 56:777-785

Westheide W (1999) Ultrastructure and functional significance of intestinojunctional spermathecae in enchytraeids (Oligochaeta, Annelida). Hydrobiologia 406:199-211 